\title{
The State of the Art of Underwater Wet Welding Practice: Part 1
}

\author{
This paper chronicles advancements in steel wet welding from the past ten years
}

BY E. C. P. PESSOA AND S. LIU

\begin{abstract}
Developments in underwater wet welding (UWW) over the past four decades are reviewed, with an emphasis on the research that has been conducted in the last ten years. Shielded metal arc welding with rutile-based coated electrodes was established as the most applied process in the practice of wet welding of structural steels in shallow water. The advancements achieved in previous decades had already led to control of the chemical composition and microstructure of weld metals. Research and development in consumables formulation have led to control of the amount of hydrogen content and the level of weld porosity in the weld metal. The main focus of research and development in the last decade was on weldability of naval and offshore structural steels and acceptance of welding procedures for Class A weld classification according to American Welding Society D3.6, Underwater Welding Code. Applications of strictly controlled welding techniques, including new postweld heat treatment procedures, allowed for the welding of steels with carbon equivalent values greater than 0.40 . Classification societies are meticulously scrutinizing wet welding procedures and wet weld properties in structural steels at depths smaller than $30 \mathrm{~m}$ prior to qualifying them as Class A capable. Alternate wet welding processes that have been tested in previous decades - such as friction stir welding, dry local habitat, and gas metal arc welding have not achieved great success as originally claimed. Almost all of the new UWW process developments in the last decade have focused on the flux cored arc welding (FCAW) process. Part 1 of this paper covers developments in microstructural optimization and weld metal porosity control for UWW. Part 2 discusses the hydrogen pickup mechanism, weld cooling rate control, design, and qualification of consumables. It ends with a description of the advancements in FCAW applications for UWW.
\end{abstract}

\section{KEYWORDS}

- Underwater Wet Welding (UWW) • Welding Metallurgy

- Welding Procedure Development • Porosity Mitigation

- Hydrogen Control • Consumables Development

\section{Introduction}

This paper focuses on the advancements in wet welding of steels that were accomplished in the last ten years. This process is performed with no mechanical barrier between the water and the welding arc. The principal advantage of the process is its intrinsic simplicity, which allows it to be applied even in the most geometrically complex structures (Refs. 1-6).

The first comprehensive paper on underwater welding was published in 1976 (Ref. 7), and other important studies were published between 1990 and 2000 (Refs. 1, 2, 8-10). In 2001, Rowe and Liu (Ref. 11) conducted extensive research containing experimental underwater wet welding (UWW), and they provided the results in detail. In the 2000s, there was some minor research conducted on UWW, but it did not include in-depth reporting of experimental work data (Refs. $5,12,13)$. Additionally, UWW was discussed at the $3^{\text {rd }}$ International Workshop on UWW held on November 2010 in Houston, Tex., during which some research was reported and future trends were discussed (Ref. 15). The last important research in this field was performed in 2012 (Ref. 16) by Liu et al. and is included in the American Welding Society (AWS) Welding Handbook.

This research highlights current developments in UWW processes. It shows that the progress made in previous decades has allowed researchers in the past ten years to develop state-of-the-art UWW processes. Part 1 of this paper focuses on consumable composition optimization. Part 2 discusses UWW weldability, consumables and procedure qualification, and alternate wet welding processes. The authors of this research aim to share this knowledge regarding recent developments in the art of wet welding with practicing welding engineers and researchers.

\section{Consumable Composition Optimization - Microstructural Optimization}

In no other welding process does the chemical composition of the weld metal change so much with ambient pressure as in wet welding. Studies performed by Ibarra, Grubbs, 


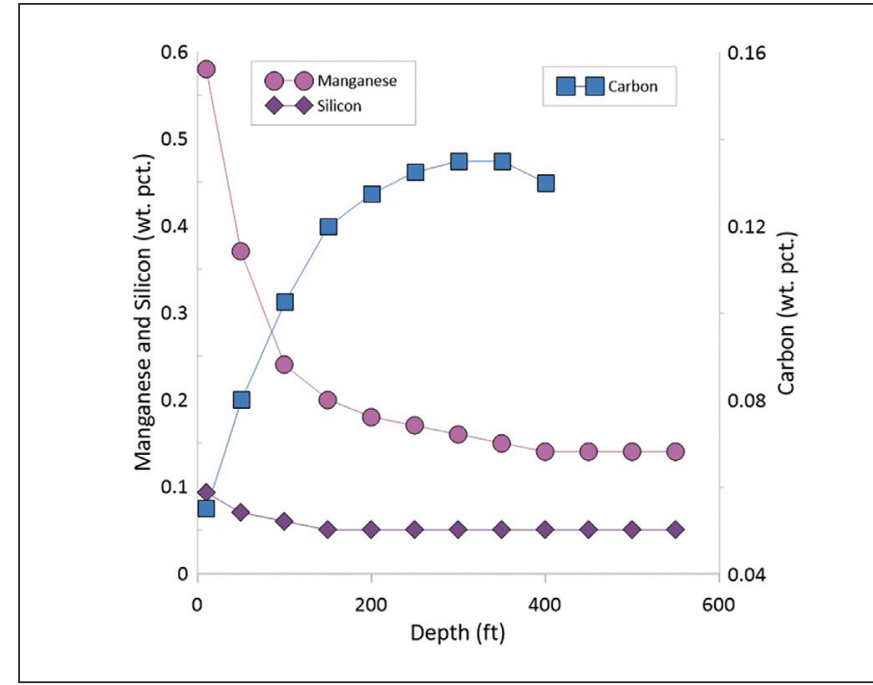

Fig. 1-Underwater wet weld metal manganese and silicon contents as a function of water depth (Ref. 20).

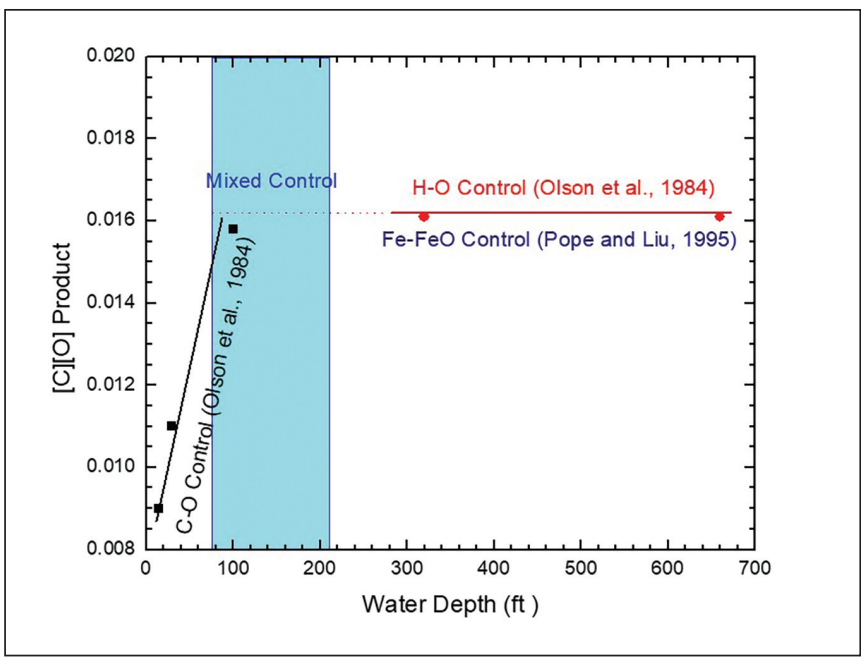

Fig. 3-Product of [C][O] as a function of depth (Refs. 20, 21).

and Olson (Ref. 17) on the metallurgical aspects of UWW reported that weld metal manganese contents reduced by as much as $250 \%$ going from the surface to a $300-\mathrm{ft}$ (91.4-m) water depth. Silicon experienced a 50\% loss in the same depth range - Fig. 1. After a certain water depth, (e.g., 200 $\mathrm{ft}$ ), the weld deposit was described as essentially iron with very small amounts of manganese and silicon. With such large changes in manganese and silicon content, the weld metal microstructure and mechanical properties were expected to change accordingly.

Hyperbaric welds that are conducted in pressurized chambers according to water depth but maintained at an essentially dry atmosphere presented similar trends regarding $\mathrm{Mn}$ and $\mathrm{Si}$, both of which decreased with increasing water depth (Ref. 18). Carbon, on the other hand, showed a small decrease instead of the increase observed in underwater wet welds. An important consequence from the observations made in wet and hyperbaric welds was the proposal of developing consumables for separate water-depth ranges (Ref. 19).

Olson and Ibarra (Ref. 20) also found that, aside from

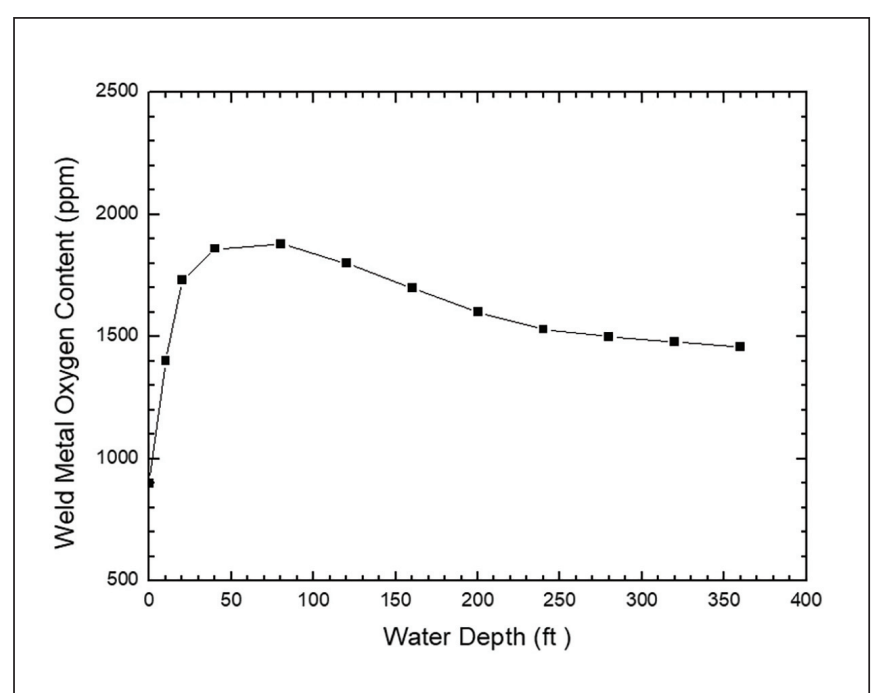

Fig. 2 - Underwater wet weld metal oxygen as a function of depth (Ref. 20).

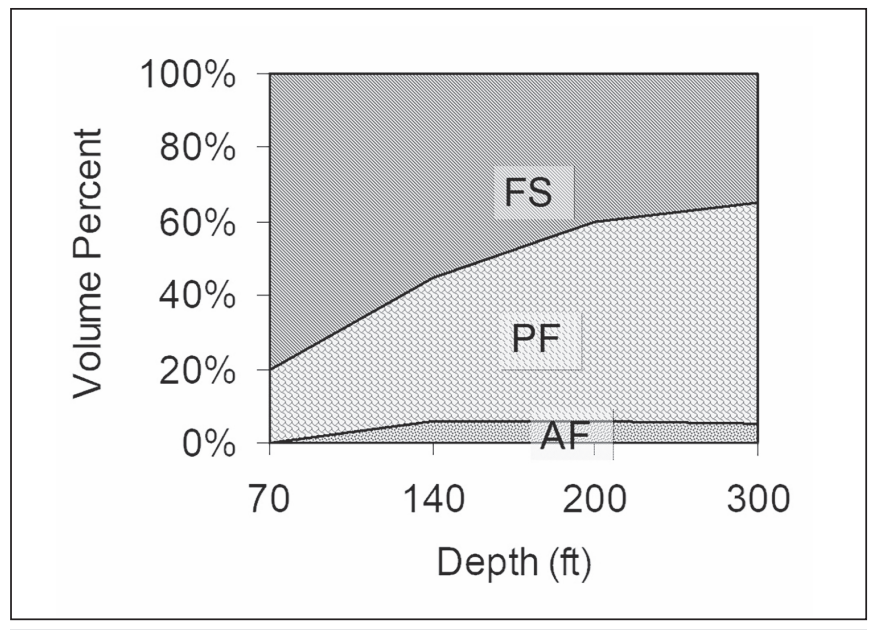

Fig. 4-Underwater wet weld microstructure of rutile-based electrodes as a function of water depth (Ref. 28).

manganese and silicon, carbon appeared to increase with the water depth for welds made with rutile electrodes, as shown in Fig. 1. They found that as the water depth increased, there was less carbon loss because of a complex interaction between alloying elements ( $\mathrm{Mn}, \mathrm{Si}), \mathrm{Fe}$, and $\mathrm{C}$. After about a 200-ft (61.0-m) water depth, $C$ remained approximately constant even though the $\mathrm{P}_{\mathrm{CO}} / \mathrm{P}_{\mathrm{CO} 2}$ ratio showed carburizing conditions.

Oxygen measurements also revealed an interesting relationship with water depth - Fig. 2 (Refs. 17, 20). As the depth increased, the oxygen increased rapidly until about 50 $\mathrm{ft}(15.2 \mathrm{~m})$, where it tended to level off. Pope and Liu (Ref. 21) as well as Pérez-Guerrero and Liu (Ref. 22) later confirmed this trend, even when using different groups of electrodes. Pope and Liu used oxidizing electrodes (Ref. 21), whereas P'erez-Guerrero and Liu utilized modified oxidizing electrodes with alloying additions (Ref. 22). The electrodes used prior to this were the rutile type (Refs. 17, 20).

Examining the $C$ and $O$ data, Olson and Ibarra (Ref. 20) plotted the product $[\mathrm{C}][\mathrm{O}]$ with pressure and found a linear 


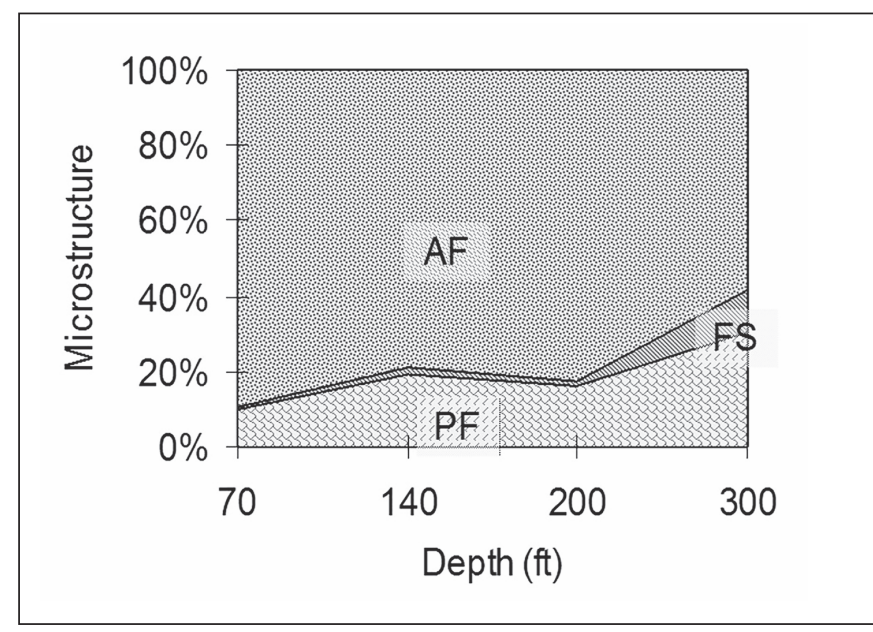

Fig. 5- Underwater wet weld microstructure of rutile-based electrodes with optimized $\mathrm{Fe}-\mathrm{Mn}$ and Ti-B as a function of water depth (Ref. 28).

relationship indicating that a $\mathrm{C}-\mathrm{O}$ reaction in the first $100 \mathrm{ft}$ $(30.5 \mathrm{~m})$ controls the chemistry of the weld pool. At greater depths, the $[\mathrm{C}][\mathrm{O}]$ became constant, indicating that the weld pool chemistry was no longer controlled by the $\mathrm{C}-\mathrm{O}$ reaction - Fig. 3. They proposed that the $\mathrm{H}-\mathrm{O}$ reaction became the controlling mechanism for greater depths (Ref. 23).

The $C$-O reaction in the weld pool at $10 \mathrm{~m}$ sea water (msw) appeared to obey chemical thermodynamics (Ref. 24), and the UWW weld metal microstructure strongly depended on this reaction. The $\mathrm{Fe}-\mathrm{O}$ reaction control proposed by Pope and Liu (Ref. 21) at greater depths relies on the amount of slag and Fe that varies accordingly even though the composition remains constant.

In the period between the 1970s and 1990s, it was generally recognized that the wet steel weld microstructure was generally coarse with grain boundary ferrite, side-plate ferrite, and ferrite with an aligned second phase (Refs. 25-27). The understanding of interactions between alloying elements and flux systems in the welding arc and weld pool allowed for the design of consumables with proper alloying contents such that as-solidified weld metal microstructures became optimized. Rowe et al. (Ref. 28) showed that welds made with rutile-based electrodes at a 70-ft (21.3-m) water depth contained $80 \%$ ferrite with second phase (FS) and $20 \%$ primary ferrite (PF). At $300 \mathrm{ft}(91.4 \mathrm{~m})$, they contained $55 \%$ PF, 40\% FS, and only 5\% acicular ferrite (AF) - Fig. 4.

Strategies developed and tested to modify wet weld microstructures included the following: 1) increases in alloy hardenability; 2) increases in acicular ferrite nucleation sites; and 3 ) poisoning of the prior austenite grain boundaries. It was recognized that the coarse microstructure was mainly a result of the loss of $\mathrm{Mn}$ and Si with the increasing water depth (Refs. 17, 20, 29), thus replenishing Mn was attempted as the first approach. From studies in the 1980s on titanium and boroncontaining consumables, Ti-based inclusions were reported to nucleate acicular ferrite more effectively. Boron atoms, diffusing to the prior austenite grain boundaries, were able to poison those sites against grain boundary ferrite nucleation. Therefore, Ti and B were also added to the welds (Refs. 23, 24, 28). As a result, designed electrodes with optimized Fe-Mn

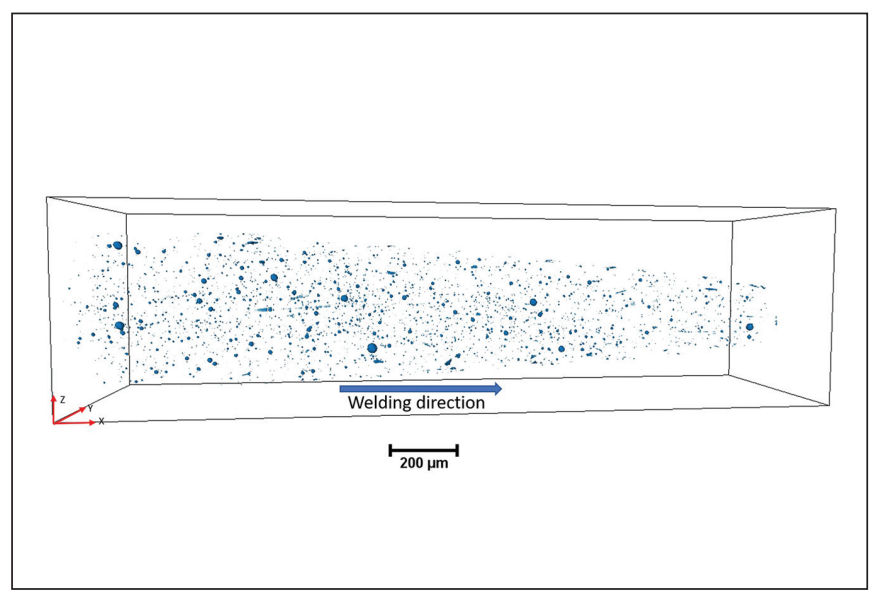

Fig. 6-3D imaging and rendering of inclusions in the weld metal deposited by rutile-type electrodes at a 0.5-m water depth by synchrotron microCT. (Courtesy of Dr. Valter dos Santos and Prof. Sidnei Paciornik.)

and Ti-B contents produced weld metal microstructures with almost $90 \%$ of AF at a $70-\mathrm{ft}(21.3-\mathrm{m})$ water depth. Even at a $300-\mathrm{ft}(91.4-\mathrm{m})$ water depth, as much as $60 \% \mathrm{AF}$ was observed (Ref. 28) - Fig. 5.

Recent work published by Liu et al. included a similar study on manual metal arc consumable development for UWW. The effects of Mo, Ti, and B introduced into the flux coatings of 4$\mathrm{mm}$-diameter electrodes were examined in welds performed at a 3-m water depth (Ref. 30). The results indicated that the addition of Mo depressed the formation of coarse proeutectoid ferrite. Acicular ferrite nucleation increased with the combined addition of Ti and B, as shown in previous work by Rowe et al. (Ref. 28). The deposited weld metal with an optimum alloy composition ratio (Ti content between 0.016 and 0.018 wt$\%$ ) achieved a tensile strength of $592 \mathrm{MPa}$, an impact toughness of $53.3 \mathrm{~J}$ at $0^{\circ} \mathrm{C}$, and a maximum elongation of $16.2 \%$.

Another landmark UWW development reported in the last decade was the replacement of usual binders (sodium and potassium silicates) applied in fabrication of shielded metal arc welding (SMAW) electrodes by polymers to make the electrodes impermeable in water (Ref. 14). SMAW electrodes produced with water-based binders need to be insulated with external varnish layers before their use in underwater wet welding. As reported in multiple research, the substitution of the binder in rutile-based electrode formulations not only avoided the insulation step for the electrodes but also induced an increase in the amount of acicular ferrite in the weld metal (Refs. 14, 31-33). Polymeric binders were able to coat and insulate individual flux particles, making their morphology more uniform to produce a smoother electrode surface. The closed fissures and sealed electrode surface resulted in low moisture absorption (Ref. 34).

\section{Discontinuities in UWW}

In underwater wet welds, there are three principal kinds of discontinuities - pores, cracks, and inclusions. They occur in a wide range of sizes (from $\mathrm{nm}$ to tens of microns), shapes (elongated, platelet, and spherical), orientations (aligned and not aligned), and spatial distributions (Refs. 35-37). 


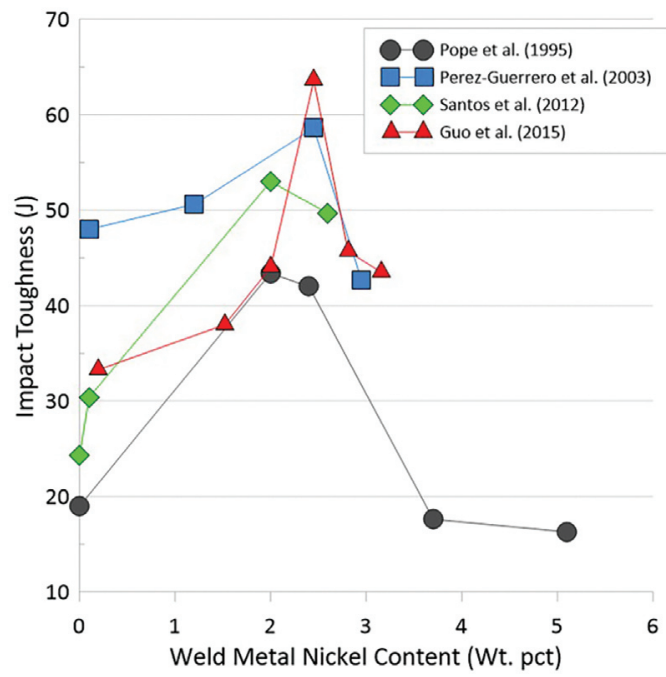

Fig. 7-Impact toughness as a function of Ni addition in welds produced by oxidizing (Ref. 39), rutile (Ref. 40), oxyrutile (Ref. 6), and unknown (Ref. 41) electrodes.

With increasing water pressure, the oxygen content in the weld metal tends to reach its solubility limit and react with deoxidizer elements in steel (Fig. 2), leading to the formation of spherical oxide inclusions (Ref. 37). Synchrotron tomography and focused ion beam scanning electron microscopy (FIB-SEM) can be used in the characterization of inclusions (Ref. 37). Volume measurements using FIB-SEM (Fig. 6) showed that inclusions occupy 0.12 to 1.54 vol-\% of the weld metals produced with rutile and oxidizing electrodes. This reported range of volumes reveals that inclusions can play a role in UWW weld metal mechanical properties.

Because of the porosity, low-alloying content, and large number of second-phase particles, impact toughness of wet welds is typically low. In fact, to classify as AWS Class A welds (Ref. 38) for 70-ksi yield strength materials, the welds must exhibit $15 \mathrm{ft}-\mathrm{lb}$ when tested at $32^{\circ} \mathrm{F}$. Pope et al. (Ref. 39) added $\mathrm{Ni}$ to oxidizing electrodes to improve the impact toughness of wet welds to more than $30 \mathrm{ft}-\mathrm{lb}$ when tested at $28^{\circ} \mathrm{F}$. The welds were produced at a $0.3-\mathrm{m}$ water depth, and nickel was chosen because it is one of the most stable elements that goes directly to the weld pool (not reacting in the arc atmosphere). They attributed the increase in impact toughness to grain refinement and the stacking-fault energy increase that facilitated the cross slip of dislocations. Pérez-Guerrero et al. (Ref. 40) added Ni into rutile-based electrodes, which further increased the impact energy to almost $45 \mathrm{ft}-\mathrm{lb}$.

Dos Santos et al. (Ref. 6) reported Ni content varying between 0.02 and $2.0 \mathrm{wt}-\%$ in weld metal deposited by electrodes covered with an oxy-rutile formulation at 0.5 - and 10-m water depths. It was reported that the weld metal tensile strength and impact toughness at $0^{\circ} \mathrm{C}$ reached $547 \mathrm{MPa}$ and $42.3 \mathrm{~J}$, respectively. The mechanical property values achieved show that research results produced in previous decades were solid and reproducible. The technology was sufficiently robust to be transitioned to production.

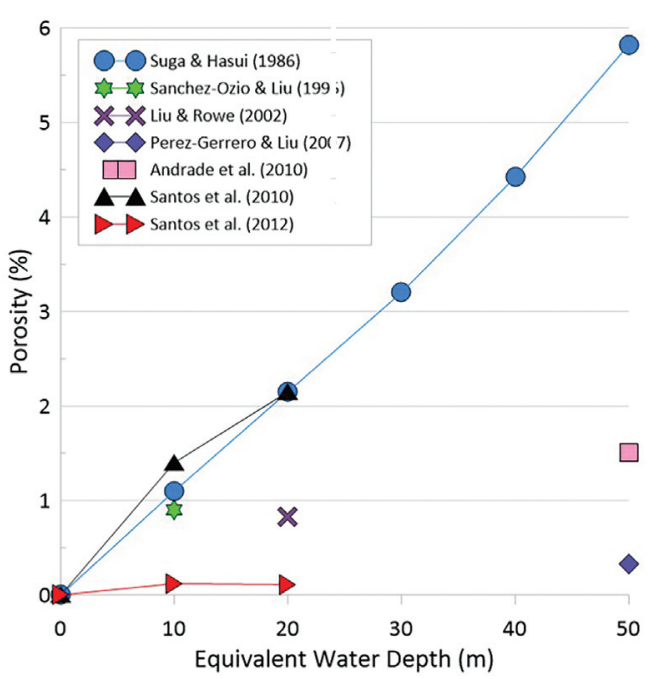

Fig. 8 - Effect of pressure on the weld metal average porosity using the following electrodes: commercial (Refs. 44, 45), $\mathrm{CaCO}_{3}$ additions (Refs. 24, 46, 47), low T-low B (Ref. 28), low carbon (Ref. 49), ultra-low carbon (Refs. 22, 50), and oxy-rutile (Ref. 6).

In 2015, Guo et al. (Ref. 41) produced a very similar work to those produced in 1995 (Ref. 39) and 2003 (Ref. 40) by Pope et al. and Pérez-Guerrero et al., respectively. These authors analyzed joints produced by welder divers at a 3-m freshwater depth using optical microscopy, $\mathrm{x}$-ray fluorescence, SEM, and energy dispersive spectroscopy. The emphasis was placed on studying the effect of the Ni content on the variation of the microstructure, tensile strength, and low-temperature toughness of the underwater wet weld joint. Their results showed an optimized impact toughness that reached $63.59 \mathrm{~J}$ at $0^{\circ} \mathrm{C}$ and $14 \%$ elongation (all weld metal tensile) when $2.45 \mathrm{wt}-\% \mathrm{Ni}$ was added to the weld metal. These researchers also reported that when the $\mathrm{Ni}$ content was between 2.04 and $2.45 \mathrm{wt}-\%$, more than $30 \%$ $\mathrm{AF}$ was found in the weld metal. These results also confirmed findings from previous research studies, which are summarized in the graph plotted in Fig. 7.

\section{Elucidation of the Porosity Formation Mechanism in Wet Welds}

Studies developed in previous decades concluded that $\mathrm{CO}$ formation, $\mathrm{H}$ diffusion to the pores, and short-circuiting transfer are responsible for pore growth in underwater wet weld metal (Refs. 4, 45, 49, 54).

Another factor that plays a role in the level of weld metal porosity is the slag as well as its behavior and properties. Slag/metal chemical reactions are also important in transferring alloying elements, reducing hydrogen content, and deoxidizing molten weld metal (Refs. 21, 39, 42). Uniformly distributed slag assists in shaping the weld deposit. The viscosity of the liquid slag controls its fluidity and, consequently, its covering ability and the shape of the weld bead, which allows for out-of-position welding. The difference in linear expansion coefficients between the weld metal and the slag controls slag 


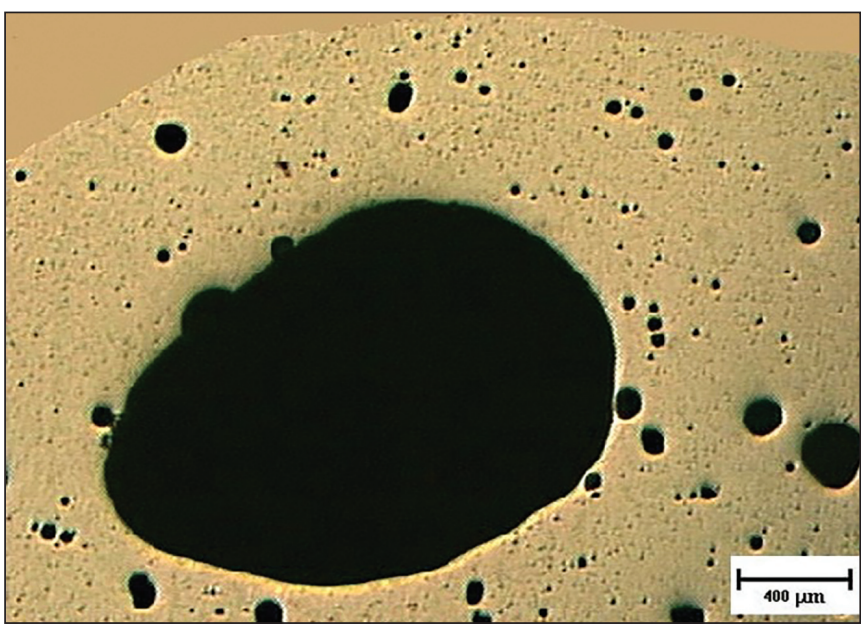

Fig. 9 - Different pore sizes in a cross section of a UWW Vgroove weld produced at a 20-m water depth using an E6013 commercial electrode (Ref. 52).

detachability (Ref. 43). Detachability of the slag is also controlled by its lattice and bonding nature. The crystal lattice and welding direction produce slag layers that automatically tilt or are accompanied by transverse cracking after welding. Good slag removal was reported when titania crystals were formed in an amorphous slag matrix (Refs. 22, 42, 43).

Slag physical features basically depend on the compositions of the main elements in the solidified slag, denominated as the slag system. The $\mathrm{TiO}_{2}-\mathrm{SiO}_{2}-\mathrm{CaO}$ slag system is the most commonly used in UWW due to its physicochemical properties. This system presents viscosity that results in a good covering (consistent thickness), a homogeneous surface of the weld beads, good detachability, and good mechanical properties of the weld metal.

Other systems studied and applied in UWW are $\mathrm{Fe}_{2} \mathrm{O}_{3}$ $\mathrm{SiO}_{2}-\mathrm{CaO}$ and $\mathrm{Fe}_{2} \mathrm{O}_{3}-\mathrm{TiO}_{2}-\mathrm{SiO}_{2}$ (Ref. 6). As alloying elements formed oxides, $\mathrm{Fe}_{2} \mathrm{O}_{3}$-based systems did not present good slag detachability, and mechanical properties of the weld metal were found to be inferior to the $\mathrm{TiO}_{2}$-based systems. On the other hand, it presented low-diffusion hydrogen in the weld metal. Another system that presented lowdiffusion hydrogen was the one based on $\mathrm{CaF}_{2}$. The basicity index of a slag system represents an approximate numerical value of the degree of polymerization in a complex oxide melt. The ratio of network modifiers to network formers in the slag system can classify it as acid, basic, or neutral (Ref.

Table 1 - Area and Number of Pores Measured in a Cross Section of BOP Deposited at Two Different Water Depths (Refs. 52, 53)

\begin{tabular}{cccccc}
$\begin{array}{c}\text { Electrode and } \\
\text { Polarity }\end{array}$ & \multicolumn{2}{c}{$\begin{array}{c}\text { Size of Pores } \\
\left(\mathrm{mm}^{2}\right)\end{array}$} & \multicolumn{2}{c}{ Number of Pores } \\
& $50 \mathrm{~m}$ & $100 \mathrm{~m}$ & $50 \mathrm{~m}$ & $100 \mathrm{~m}$ \\
\hline E6013 DCEP & 0.04 & 0.17 & 7.0 & 20.4 \\
E6013 DCEN & 0.28 & 0.34 & 14.3 & 31.4 \\
E7024 DCEP & 0.58 & 0.68 & 10.8 & 21.6 \\
E7024 DCEN & 0.79 & 0.70 & 11.8 & 27.7 \\
E7018 DCEP & 0.55 & 0.43 & 10.1 & 24.6 \\
E7018 DCEN & 0.26 & 1.29 & 18.0 & 19.3 \\
\hline
\end{tabular}

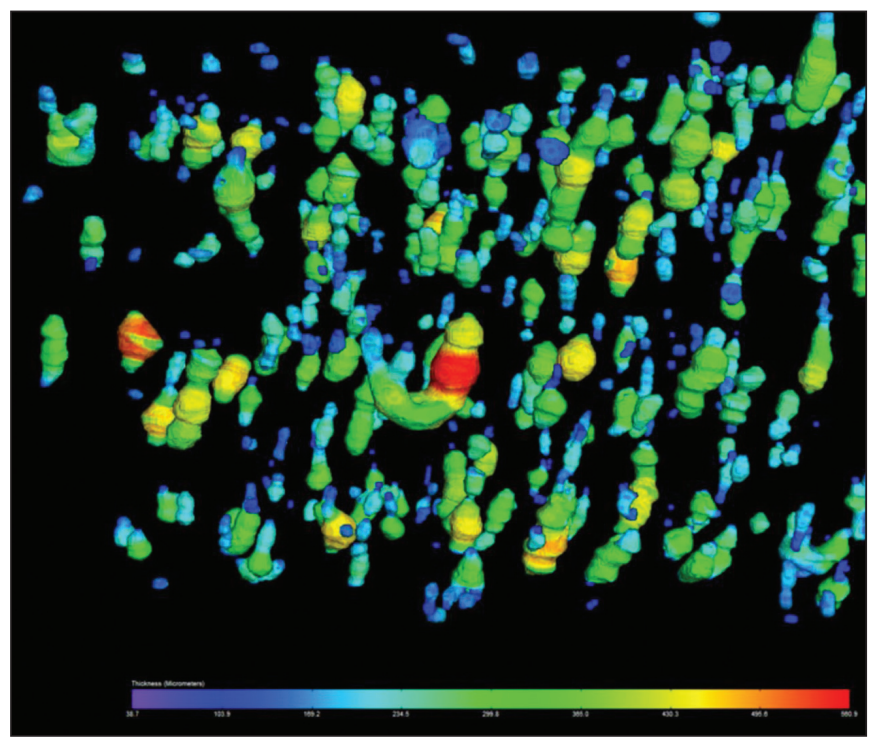

Fig. $10-3 D$ rendering of the detected pores. Pores are elongated and aligned orthogonally to the welding direction. (Courtesy of Dr. Valter dos Santos and Prof. Sidnei Paciornik.)

28). Medeiros and Liu (Ref. 42) as well as Rowe et al. (Ref. 28) showed that in a slag of neutral basicity, the amounts of hydrogen and oxygen reduced in the arc atmosphere and weld pool, which reduced the weld metal porosity. They also proposed that water vapor solubility in slags, breakdown of silicate networks, and oxidation of carbon and hydrogen in the weld pool were minimized in a slag system of neutral basicity, which also reduced weld metal porosity.

Medeiros and Liu (Ref. 42) studied the effect of hydrogen pickup by the slag on the weld metal diffusible hydrogen content for SMAW in both direct current electrode positive (DCEP) and direct current electrode negative (DCEN) polarities. The chemical analyses showed the weld metal hydrogen pickup was strongly dependent on the solubility of water in the slag systems. The total and diffusible hydrogen content in the weld metal increased monotonically with the increasing slag hydrogen content. The slag/metal interface was identified as being responsible in controlling the weld metal hydrogen pickup. The model assumed hydrogen was present in the slag as $(\mathrm{OH})^{-}$ions, and $\mathrm{FeO}$ displayed an ideal solution behavior. The $\mathrm{x}$-ray diffraction conducted on different slags showed the lower diffusible hydrogen values were always associated with the presence of fayalite $\left(2 \mathrm{FeO} \cdot \mathrm{SiO}_{2}\right)$.

The slag acts as an insulating layer to protect the cooling weld metal from direct contact with the water. The physical characteristics of the slag, such as regular/constant thickness, can allow for the escape of trapped gases from the molten pool (Ref. 22). Slag slows down the cooling while giving enough time for degassing to occur. The solidified slag exhibits holes through which the gas evolved from the weld. In UWW conditions, due to fast cooling times, not all the gases are allowed to escape from the molten steel, resulting in weld porosity. The liquid slag that covers the weld metal produces better thermal conditions for degassing the weld metal even in wet welding at very shallow water depths. Pérez-Guerrero and Liu (Ref. 22) suggested the reason for the absence of pores when welds were deposited at very shallow water depths (i.e., less than $5 \mathrm{~m}$ ) was 


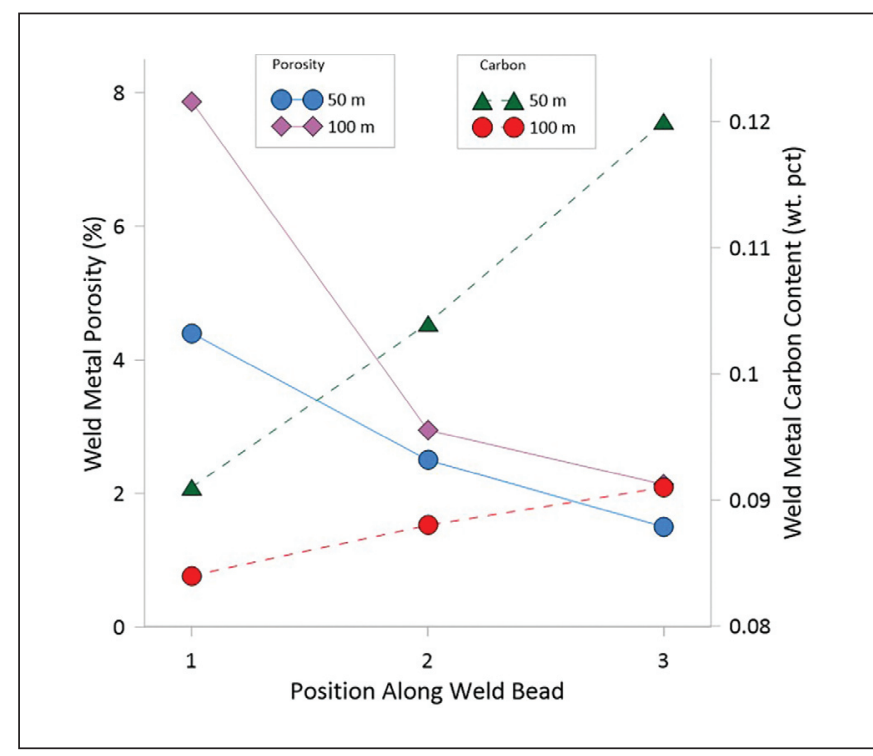

Fig. $11-$ Average porosity and carbon content along the weld beads deposited at water depths of 50 and $100 \mathrm{~m}: 1-$ Beginning of weld beads; 2 - middle of weld beads; 3 - end of weld beads (Refs. 6, 59, 60).

due to the slag, under the protection of a steam bubble surrounding the arc, as well as the low pressure in the arc, which allows degassing of gases entrapped in the weld metal.

In 1986, Suga and Hasui (Ref. 44) studied the relationship between porosity and water pressure (depth) using high titanium oxide, ilmenite, and iron-iron oxide-type electrodes. High numbers such as 8 and 9 vol-\% porosity were reported. At a water depth of approximately 165-ft (50-m), about 6 vol-\% porosity was determined - Fig. 8 .

Sanchez-Osio et al. (Refs. 24, 46) tested the effect of calcium carbonate in addition to rutile-based coatings. As calcium carbonate decomposed, gases such as $\mathrm{CO}_{2}, \mathrm{CO}$, and $\mathrm{O}_{2}$ formed in the arc, reducing the activity of hydrogen in the plasma. The authors observed a minimum in porosity with 12.5 wt-\% calcium carbonate addition to the electrode covering for welds deposited at a 10-m water depth. This study showed the amount of porosity can be minimized by reducing the hydrogen content of wet welds - Fig. 8.

Rowe et al. (Ref. 28) tested ferroalloy additions such as ferromanganese, ferrotitanium, and ferroboron to rutile-based coatings. Higher levels of ferromanganese addition produced less porous welds in most cases. Controlled additions of titanium and boron reduced the pore size. By applying strong deoxidizers, it was possible to prevent weld metal porosity that originates from carbon monoxide and steam. An important result observed in this work was that both the porosity and hydrogen content of the weld metal decreased as the slag basicity was adjusted toward a more neutral value. Slag basicity also controlled the weld metal oxygen, and this effect may be related to the water-vapor solubility minimum in slags near neutral basicity.

Pérez-Guerrero and Liu (Ref. 22), Liu and Rowe (Ref. 50), and Andrade et al. (Ref. 49) tested different levels of carbon on the steel rods of rutile-based coatings. The results obtained in these works, shown in Fig. 8, demonstrated that by reducing the carbon content of the rods, $\mathrm{CO}$ gas bubbles do

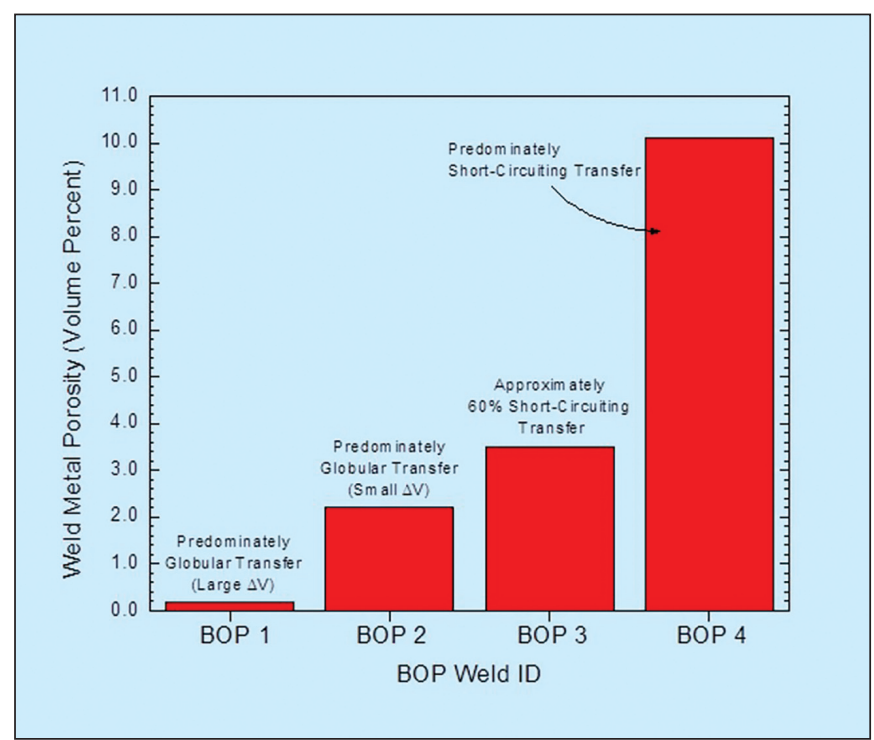

Fig. 12 - Weld metal porosity measured in weld beads deposited in different transfer modes (Ref. 22).

not nucleate and grow in the molten droplets and will not be later transported into the weld pool.

Dos Santos et al. (Ref. 6) tested additions of hematite and rutile to oxy-rutile-based coatings. Hematite decomposed to form FeO in the slag, increasing slag basicity as well as weld metal hydrogen pickup (in a slag of neutral basicity). Additionally, the water vapor solubility in the slag went to a minimum value. By applying all the concepts studied in previous works, the porosity values measured and shown in Fig. 8 were very low for welds deposited in a water depth up to $20 \mathrm{~m}$.

Pope et al. (Ref. 45) and Pessoa et al. (Ref. 4) reported adverse effects of porosity on the mechanical properties of underwater wet weld metal. The results indicated that porosity decreased the tensile strength, ductility, and toughness. Pope et al. (Ref. 45) reported average porosity values ranging from 0.5 vol-\% at a $0.3-\mathrm{m}$ water depth to 0.85 vol-\% at a 20-m water depth in wet welds deposited with 3.2-mmdiameter oxidizing electrodes. Pessoa et al. (Ref. 4) and Liu et al. (Refs. 52, 53) tested 5-mm-diameter commercial electrodes in both DCEP and DCEN polarities in wet conditions. They reported porosity amounts of $1.2,8.4$, and 13.1 vol-\% in bead-on-plate (BOP) deposited with E6013 electrodes at 50,100 , and $150-\mathrm{m}$ water depths, respectively. They reported values of 7.3, 14.9, and 20.1 vol-\%, respectively, for BOP deposited with E7024 electrodes under similar conditions. BOP welds deposited with E7018 electrodes presented striking porosity values varying from 16.8 vol- $\%$ at a 50 -m water depth to 20.2 vol-\% at a $100-m$ water depth. They also reported higher porosity amounts measured in BOP welds deposited with DCEN polarity using the same electrodes and conditions.

As porosity is a determining factor of the mechanical performance of structural welds, the main target of most of the investigations accomplished before the 1980s was to decrease the porosity. With those studies, the origin of the pores was also determined.

Ibarra, Liu, and Olson (Ref. 8), using nucleation and growth analysis developed by Trevisan et al. (Ref. 51), tried to explain 
the porosity behavior with water depth. They stated the critical radius to nucleate a pore increases with water depth, making the pore formation more difficult during welding in a water environment. For a gas bubble to nucleate, the partial pressure of the gas inside the bubble $P_{g}$ has to be greater than the sum of the atmospheric pressure $P_{a}$, the hydrostatic pressure $P_{h}$, and the capillary contribution $(2 \gamma / r)$ to the pressure, as shown in Equation 1 (Refs. 51, 8, 22):

$$
P_{g}>P_{a}+P_{h}+2 \gamma / 2 r
$$

where $\gamma$ is the steel surface tension and $r$ is the radius of the droplet. So, the weld metal porosity behavior reported by Suga and Hasui (Ref. 44) is contrary to the theoretical thermodynamics prediction, suggesting weld underwater metal porosity depends less on external pressure and more on chemical reactions that generate gases in the weld pool. The size distribution and shape of the pores may be affected by the hydrostatic pressure (Refs. $44,54,55$ ). The porosity values reported in Fig. 8 do not give any indication of the population of pores. Figure 9 shows a cross section of a V-groove weld deposited at a 20-m water depth using an E6013 electrode. It is possible to see the wide range of pore sizes and different distributions in the same sample. Pessoa et al. (Ref. 4) as well as Liu and Pérez-Guerrero (Refs. 52, 53) performed extensive studies on porosity occurrence in BOP welds deposited by three different electrode types (AWS E6013, E7024, and E7018) and DCEP and DCEN polarities and at simulated water depths of 50 and $100 \mathrm{~m}$ (164 and $328 \mathrm{ft}$ ). These results are shown in Table 1 . They found that all deposits presented more than a $100 \%$ increase in the measured number of pores. The measured average pore size indicated a significant variation for the E6013 electrode in DCEP. These results confirmed that nucleation, coalescence, and the shape of pores depend on water pressure.

The gas composition contained in the underwater wet weld metal pores was measured (Refs. 44, 54-56), and the thermodynamic calculations were performed (Ref. 57). The amounts found were scattered but proved that the atmosphere of pores is formed mainly by hydrogen, with values ranging from 45 to 96 vol-\% in the measurements and from 20 to 30 vol-\% in the calculations. The CO presented measured values between 0.4 and 24 vol-\%, and the $\mathrm{CO}_{2}$ presented values between 0 and 6 vol- $\%$.

Hydrogen and other gases induce the formation of elongated pores in the weld metal (Fig. 9) and are oriented in the solidification direction. The elongation is an indication that the gas evolution rate is comparable to the molten weld metal solidification rate. The chemical species are able to reach the pores to keep the growth characterized by solidification (Ref. 44). Pore numbers increase with the welding depth, as the partial pressure of hydrogen increases with the water pressure, as shown in Fig. 8. Padilla et al. (Ref. 36) and Silva et al. (Ref. 37) used a laboratory-scale x-ray microCT to analyze pores as well as specific 3D image processing and analysis routines to render $3 \mathrm{D}$ images of the pores for measurements. Figure 10 shows a 3D rendering of the detected pores in a $5 \mathrm{~mm}^{3}$ weld metal sample. They found values of 1.44 vol- $\%$ and 122 pores for welds produced at a $10-\mathrm{m}$ water depth as well as 1.18 vol-\% and 508 pores for welds produced at a 20 -m water depth using rutile commercial electrodes. This porosity result is contrary to the ones reported in Fig. 8. The sample size used in this work was very small $\left(5 \mathrm{~mm}^{3}\right)$, and only one sample for each condition was used to measure porosity. This is a new method that can be used to measure porosity in UWW, but it requires a larger sampling size to properly represent the porosity observed in the weld bead statistically.

Sanchez-Osio et al. (Refs. 24 and 47) established the dependence of porosity on the [C][O] partial pressure (chemical activities) product. They applied the concepts developed by Chew (Ref. 58), who studied the effects of calcium carbonate additions to the flux coating of covered steel electrodes on weld metal porosity. They reported that porosity decreased by approximately 1.5 vol- $\%$ with the increasing calcium carbonate content from 9 to 12 wt-\% in welds deposited at a 10-m water depth. The porosity level obtained with $12 \% \mathrm{CaCO}_{3}$ was approximately 1 vol-\% - Fig. 8. In the welding arc, $\mathrm{CaCO}_{3}$ decomposed into the $\mathrm{CO}$ gas that reduces the hydrogen partial pressure in the welding atmosphere, thus reducing the diffusible hydrogen amount in the weld metal (Ref. 58).

Rowe et al. (Ref. 28) investigated the effects of the alloying additions to the flux covering of SMAW electrodes. Through replenishment of $\mathrm{Mn}$, the amount of porosity decreased from almost 6 vol-\% to about 2 vol- $\%$. Thermodynamic calculations of the weld pool showed the formation of $\mathrm{MnO}$. Therefore, the deoxidation reaction minimized porosity, indicating that $\mathrm{CO}$ was responsible for the formation of porosity. Further additions of Ti and B only moderately decreased the porosity - Fig. 8.

To further substantiate that $\mathrm{CO}$ is responsible for porosity formation, experiments were performed using extra-low carbon rods with 0.005 wt-\% C. Weld beads at a $165 \mathrm{ft}(50.3$ m) water pressure showed extremely low porosity, below 1.5 vol-\%, as found in the other welds reported in the literature (Refs. 22, 50). The average porosity in these welds was about 0.3 to 0.4 vol-\%, which is also shown in Fig. 8.

A study by Andrade et al. (Ref. 49) conducted in the last decade confirmed the effect of carbon content in the base metal and core rod on UWW porosity. They verified the influence of $\mathrm{CO}$ in porosity formation. Experiments were performed using rutile commercial flux formulation extruded on low- and high-carbon rods $(0.002$ wt- $\%$ C and 0.62 wt- $\%$, respectively). BOP welds deposited at a 50-m water depth showed that the maximum porosity increased $124 \%$ on average with the increment of carbon content in the rods. These researchers related the increase in porosity to the occurrence of short-circuiting events in the metal transfer during UWW. The number of short circuits measured increased $75 \%$ with the increment of carbon content in the rods.

With certainty, CO is a major cause of weld porosity. These pores nucleate on typical nucleation sites, initially along the fusion line; along the solidification front; and on second-phase particles that are dispersed in the weld pool. $\mathrm{CO}$ bubbles that form as a result of chemical reactions in the weld pool can become sinks for hydrogen diffusion. Other gaseous-forming elements or products will tend to migrate toward, and collect in, the bubbles. Hydrogen atoms can diffuse into the bubbles and recombine to form molecular hydrogen. Thus, all bubbles will contain both $\mathrm{CO}$ and $\mathrm{H}_{2}$ (Refs. 22, 50).

As mentioned earlier, porosity was found to relate to metal transfer events. Dos Santos et al. (Ref. 6) and Pessoa et al. 
(Refs. 59,60) showed that the chemical composition of a weld metal changes along the weld length. The metal transfer mode and porosity also changed. Figure 11 shows the average porosity and carbon content variation along the weld beads deposited at water depths of 50 and $100 \mathrm{~m}$. CO formation was related to carbon content variation in the weld metal along the weld beads. Carbon atoms that are present in the arc atmosphere and weld pool can combine with oxygen and form $\mathrm{CO}$ and $\mathrm{CO}_{2}$. These gaseous molecules nucleate bubbles that get trapped in pores or escape to the slag layer. High $\mathrm{CO}$ and $\mathrm{CO}_{2}$ formation implies a reduction of carbon content in the weld metal and carbide formation. A higher carbon content found in the end part of the weld beads was strongly correlated with a decrease in porosity. Figure 12 shows weld metal porosity measured in weld beads deposited in different transfer modes (Ref. 22).

Pérez-Guerrero and Liu (Ref. 22) reported that welds deposited at different metal transfer modes contained different amounts of porosity. The droplets collected during transfer showed definite proof that short-circuiting transfer contained larger amounts of gas pores that were carried to the weld pool. The finer droplets contained fewer gas pores and less porosity after solidification (Refs. 22, 49, 50).

Bracarense et al. (Ref. 61) and Pessoa et al. (Refs. 62, 63) studied the influence of polarity and arc stability on weld metal porosity. Welds produced using the SMAW process with rutile-grade electrodes under the DCEP configuration exhibited a lower porosity and shallow penetration. The oxidizing-grade electrodes presented the opposite behavior.

Several studies were published about porosity distribution along the weld beads (Refs. 6, 59, 60) and porosity location on the weld bead (Ref. 64). Porosity was found to decrease along the longitudinal axis of the weld bead, and this change was related to the increase in carbon content in the weld metal and reduction of short-circuiting events in the metal transfer along the same direction. Pessoa et al. (Refs. $59,60)$ tried to reduce the porosity in the final weld metal by melting the previous pores, grinding previous weld passes, or changing the metal transfer mode.

Decades of studies proved that wet weld metal porosity can be minimized by reducing hydrogen and $\mathrm{CO}$ by means of adding deoxidizers, hydride formers, and oxygen-potential modifiers to the consumable electrodes. Advances in porosity mitigation made the wet welding technique an underwater structural repair option (Ref. 65).

Recent studies (Ref. 6) reported porosity values of about 0.05 vol-\% in welds produced at a $10-\mathrm{m}$ water depth using oxy-rutile electrodes (low hydrogen and carbon). Researchers stated that not only was porosity responsible in reducing elongation values on tensile test samples, but hydrogen also induced transverse cracking on underwater welded metal.

\section{Summary}

After organizing all results obtained from the literature on UWW and reviewing published developments on UWW over the past four decades, with special emphasis on the advancements achieved in the most recent decade, it is possible to summarize the main conclusions as follows:

1) Consumable formulation and weld microstructural optimization was accomplished by understanding the govern- ing mechanisms that control the chemical composition of the weld metal in a pressurized water environment. Alloying elements such as carbon, manganese, and silicon are influenced by $\mathrm{C}-\mathrm{O}, \mathrm{H}-\mathrm{O}$, and $\mathrm{Fe}-\mathrm{O}$ reactions that occur in the welding arc. Understanding the interactions between the elements of flux systems, the high-oxygen and high-hydrogen environment, and the base metal that occurs in the arc atmosphere and the weld pool has made the designing of consumables with proper alloying contents and a refined weld metal microstructure possible. By adding specific elements into the flux (e.g., nickel) and controlling the oxygen and hydrogen content of the SMAW electrodes, it was possible to increase toughness and increase microstructures like acicular ferrite. Mechanical properties exhibited by underwater wet weld metal are at similar levels to those obtained in dry welds. The replacement of usual binders by polymers in the fabrication of SMAW electrodes allowed for the control of moisture absorption and promoted a higher toughness microstructure during UWW.

2) Discontinuities in underwater wet welds were studied and quantified. Through application of modern techniques of measuring and detection - and through new understanding of the mechanism that controls the formation of inclusion, porosity, and diffusible hydrogen - underwater wet welds presented mechanical properties and performance that adhere to all requirements of AWS D3.6, Underwater Welding Code.

3) Nonmetallic inclusions reduced weld metal mechanical properties in a manner similar to pores by interrupting the continuity of the matrix. The amount and size of inclusions were controlled by the amount of oxygen as well as the interaction between the liquid slag and the liquid weld metal. A properly designed slag system (e.g., $\mathrm{TiO}_{2}-\mathrm{SiO}_{2}-\mathrm{CaO}$ ) presented viscosity and physical characteristics that refined the weld metal before its solidification, thus reducing the amount of nonmetallic inclusions.

4) Porosity also depended on slag systems and their interaction with the weld metal. The porosity formation mechanism in UWW was elucidated. $\mathrm{CO}$ and $\mathrm{CO}_{2}$ formation in the liquid droplets and weld pool controlled the nucleation of the bubbles. Dissolved hydrogen and other gases contributed to the pore-growing process. Slag properties directly controlled the balance between weld metal solidification and pore evolution and indirectly controlled the weld bead shape and amount of degassing. The porosity in the weld metal is determined by $\mathrm{CO}$ and $\mathrm{CO}_{2}$ formation, the amount of hydrogen dissolved in the weld metal and arc atmosphere, the weld metal transfer mode, and the slag system's properties.

5) By elucidating the porosity mechanisms in UWW, it was possible to reduce porosity to levels that met all specific code requirements. Very low porosity levels were achieved by controlling $\mathrm{CO}$ and $\mathrm{CO}_{2}$ formation, the hydrogen content in the arc atmosphere and weld metal, and the liquid slags that allow gases to escape from the weld pool. The $\mathrm{Fe}_{2} \mathrm{O}_{3}-$ based flux systems produced the smallest amount of porosity, as reported in the literature. Calcium carbonate, hematite, ultra-low carbon rods, and the TiO2-SiO2-CaO slag systems have proven to be effective in reducing weld metal porosity. Conversely, short-circuiting metal transfer increased porosity in UWW. 


\section{Acknowledgments}

The authors would like to acknowledge the support provided by several funding institutes, companies, universities, and laboratories, such as the former Minerals Management Service (today called the Bureau of Safety and Environmental Enforcement), the former Global Divers and Contractors, Petróleo Brasileiro S.A., Instituto Mexicano del Petróleo, Laboratório de Robótica, Soldagem e Simulação of the Federal University of Minas Gerais, and Pontifícia Universidade Católica.

The authors would also like to thank D. L. Olson, S. Ibarra, C. E. Grubbs, M. Rowe, A. Sanchez-Ozio, Mik Else,

A. Bracarense, F. Pérez-Guerrrero, P. Szelagowski, A. Pope, R. Medeiros, and V. dos Santos for their contributions to the underwater wet welding research programs conducted at the Colorado School of Mines in the past 35 years, which produced many of the results reported in this paper.

\section{References}

1. Ibarra, S., Grubbs, C. E., and Liu, S. 1994. State of the art and practice of underwater wet welding of steel. International Workshop on Underwater Welding of Marine Structures. New Orleans, La.

2. Grubbs, C. E., and Reynolds, T. J. 1998. State-of-the-art underwater wet welding - Offshore oil fields. World Oil.

3. Kononenko, V. Y. 2000. Technologies of underwater wet welding and cutting. E. O. Paton Electric Welding Institute, Kiev, Ukraine.

4. Pessoa, E. C. P., Bracarense, A. Q., Liu, S., Pérez-Guerrero, F., and Zica, E. M. 2006. Porosity variation along multipass underwater wet welds and its influence on mechanical properties. Journal of Materials Processing Technology 179(1-3): 239-243. DOI: 10.1016/ j.jmatprotec.2006.03.071

5. Łabanowski, J., Fydrych, D., and Rogalski, G. 2008. Underwater welding - A review. Advances in Materials Sciences 8(3): 11-22. DOI: 10.2478/v10077-008-0040-3

6. dos Santos, V. R., Monteiro, M. J., Rizzo, F. C., Barcarense, A. Q., Pessoa, E. C. P., Marinho, R. R., and Vieira, L. A. 2012. Development of an oxyrutile electrode for wet welding. Welding Journal 91(12): 319-s to 328-s.

7. Tsai, C. L., and Masubuchi, K. 1977. Interpretive report on underwater welding. Welding Research Council, Bulletin No. 224: 1-37.

8. Ibarra, S., Liu, S., and Olson, D. L. 1995. Underwater wet welding of steel. Welding Research Council, Bulletin No. 401: 1-39.

9. Grubbs, C. E., Bertelmann, A. E., Ibarra, S., Liu, S., Marshall, D. J., and Olson, D. L., eds. 1996. Underwater welding and cutting. Welding Handbook, Materials and Applications, Part 1, Vol. 3: 446-500. Miami, Fla.: American Welding Society.

10. Szelagowski, P. 1991. Underwater welding — Present state and development trends. Welding and Cutting 2: 7-11.

11. Rowe, M., and Liu, S. 2001. Recent developments in underwater wet welding. Science and Technology of Welding \& Joining 6(6): 387-396. DOI: 10.1179/136217101322910560

12. Liu, S. 2004. A decade of progress in underwater wet welding using the SMAW process (1990-2003). ASME 23 ${ }^{\text {rd }}$ International Conference on Offshore Mechanics and Arctic Engineering, Vol. 2: 927-934. DOI: 10.1115/OMAE2004-51465

13. Payão Filho, J. C., Mello, R. T., Medeiros, R. C., and Paranhos, R. P. R. 2003. Histórico recente da soldagem subaquática molhada. Soldagem \& Inspeção 8(12): 102-111.

14. Menezes, P. H. R., Ezequiel, C. P. P., and Bracarense, A. Q. 2018. Comparison of underwater wet welding performed with silicate and polymer agglomerated electrodes. Journal of Materials Processing Technology (266): 63-72. DOI: 10.1016/j.jmatprotec.2018. 10.019
15. Liu, S., Olson, D. L., Else, M., and Cridland, J. M. M. 2010. International Workshop on the Art Science and Reliability of Underwater Welding and Inspection Technology, Houston, Tex. bsee.gov/sites/ bsee.gov/files/tap-technical-assessment-program//654aa.pdf

16. Liu, S., Bracarense, A. Q., Couch, W. J., Else, M., Pessoa, E. C. P., Ibarra, S., Pérez-Guerrero, F., Pope, A. M., Reynolds, T. J., Tsai, C. L., and West, T. C., eds. 2011. Underwater welding and cutting. Welding Handbook, Materials and Applications, Part 1, Vol. 4: 609-673. Miami, Fla.: American Welding Society.

17. Ibarra, S., Grubbs, C. E., and Olson, D. L. 1988. Metallurgical aspect of underwater welding. Journal of Metals 40(12): 8-10. DOI: 10.1007/BF03258786

18. Christensen, N. 1983. The metallurgy of underwater welding. Underwater Welding - IIW Conference, Trondheim, Norway: 71-94.

19. Rowe, M. D., Liu, S., and Reynolds, T. J. 1999. Development of SMAW coatings for underwater wet welding at specific depth ranges. Proceedings of the $18^{\text {th }}$ International Offshore Mechanics and Arctic Engineering Conference - Material Symposium, Newfoundland, Canada: 99-2231.

20. Olson, D. L., and Ibarra, S. 1986. Underwater welding metallurgy. First OMAE Specialty Symposium on Offshore and Arctic Frontiers, 439-447. New York, N.Y.: ASME.

21. Pope, A. M., and Liu, S. 1996. Hydrogen content of underwater wet welds deposited by rutile and oxidizing electrodes. International Conference on Offshore Mechanics Arctic Engineering, ASME 3: 85-92.

22. Pérez-Guerrero, F., and Liu, S. 2007. Explaining porosity formation in underwater wet welds. ASME $26^{\text {th }}$ International Conference on Offshore Mechanics and Arctic Engineering 4: 249-257. DOI: 10.1115/OMAE2007-29696

23. Olson, D. L., Liu, S., and Ibarra, S. 1994. Pyrometallurgy and physical metallurgy of underwater wet welds. Welding Technology in Action 2(25). Melbourne, Australia.

24. Sanchez-Osio, A., Liu, S., Ibarra, S., and Olson, D. L. 1995. Designing shielded metal arc consumables for underwater wet welding in offshore applications. Journal Offshore Mech. Arct. Eng. 117(3): 212-220. DOI: 10.1115/1.2827092

25. Liu, S., Ibarra, S., and Olson, D. L. 1991. Electrode formulation for wet underwater welding electrodes. AWS International Conference of Underwater Welding, New Orleans, La.: 98-119.

26. Ibarra, S., Olson, D. L., and Liu, S. 1991. Effect of water depth on underwater weld metal porosity formation. AWS International Conference on Underwater Welding, New Orleans, La.: 54-69.

27. Liu, S., Olson, D. L., and Ibarra, S. 1994. Electrode formulation to reduce weld metal hydrogen and porosity. 13th Offshore Mechanics and Arctic Engineering Conference, Copenhagen, Denmark: 291-298.

28. Rowe, M. D., Liu, S., and Reynolds, T. J. 2002. The effect of ferro-alloy additions and depth on the quality of underwater wet welds. Welding Journal 81(8): 156-s to 166-s.

29. Oh, D. W., Olson, D. L., and Frost, R. H. 1991. Nucleation mechanisms of acicular ferrite in low-carbon steel weld metal. Welding and Joining Processes 51: 49-61. ASME. Atlanta, Ga.

30. Liu, D., Guo, N., Xu, C., and Li, Hongliang. 2017. Effects of Mo, $\mathrm{Ti}$ and $\mathrm{B}$ on microstructure and mechanical properties of underwater wet welding joints. J. of Materi. Eng. and Perform. 26(5): 2350. DOI: 10.1007/s11665-017-2629-3

31. Gonzalez, L. P., Bracarense, A. Q., Puchol, R. Q., Pessoa, E. C. P., Pérez, M. R., and Scott, A. D. 2012. Perspectiva de uso del poliestireno expandido, como alternativa de impermeabilizante, para electrodos empleados en la soldadura subacuática mojada. Revista Facultad de Ingeniería Universidad de Antioquia 62: 103-113.

32. Scott, A. D., Bracarense, A. Q., Gonzalez, L. P., Pessoa, E. C. P., Puchol, R. Q., and Pérez, M. R. 2008. Caracterización metalografica de depósitos de soldadura obtenidos con un electrodo rutílico con capas de barniz impermeabilizante de soldadura subacuatica mojada. IIW International Congress XXXIV, Consolda 1: 1-10.

33. Fischel, I., Dalla, A., Ros, D. A., Felizardo, I., Turani, C., Gonzalez, L. P., Pérez, M. R., Puchol, R. Q., Pessoa, E. C. P., and Bracarense, A. Q. 2009. Desenvolvimento de eletrodos revestidos impermeáveis. 
XXXV Consolda - Congresso Nacional de Soldagem, Recife, Brazil.

34. Crean, S. 2018. The need for low hygroscopic welding consumables additives. Welding Journal 97(6): 68-69.

35. Paciornik, S., et al. 2012. Characterization of pores and cracks in underwater welds by $\mu \mathrm{ct}$ and digital optical microscopy. $1^{\text {st }}$ International Conference on 3D Materials Science: 177-182. Hoboken, N.J.: John Wiley \& Sons Inc. DOI: 10.1002/9781118686768.ch27

36. Padilla, E., Chawla, N., Silva, L. F., dos Santos, V. R., and Paciornik, S. 2013. Image analysis of cracks in the weld metal of a wet welded steel joint by three dimensional (3D) x-ray microtomography. Materials Characterization 83: 139-144. DOI: 10.1016/j.matchar. 2013.06.016

37. Silva, L. F., dos Santos, V. R., Paciornik, S., Mertens, J. C. E., and Chawla, N. 2015. Multiscale 3D characterization of discontinuities in underwater wet welds. Materials Characterization 107: 358-366. DOI: 10.1016/j.matchar.2015.07.030

38. AWS D3.6M:2017, Underwater Welding Code. 2017. Miami, Fla.: American Welding Society.

39. Pope, A. M., Liu, S., Teixeira, J. C. G., dos Santos, V. R., and Paes, M. T. P. 1995. Use of nickel to improve the mechanical properties of high oxygen underwater wet welds. International Conference on Offshore Mechanics and Arctic Engineering - Materials Engineering 3: 102-117.

40. Pérez-Guerrrero, F., Liu, S., Smith, C., and Rodrígues, E. 2003. Effect of nickel on toughness of underwater wet welds. $22^{\text {nd }}$ International Conference on Offshore Mechanics and Arctic Engineering, ASME: 165-170. DOI: 10.1115/OMAE2003-37261

41. Guo, N., Liu, D., Guo, W., Li, H., and Feng, J. 2015. Effect of Ni on microstructure and mechanical properties of underwater wet welding joint. Materials \& Design 77: 25-31. DOI: 10.1016/j.matdes. 2015.04.007

42. Medeiros, R. C., and Liu, S. 1998. A predictive electrochemical model for weld metal hydrogen pickup in underwater wet welds. ASME Journal of Offshore Mechanics and Arctic Engineering 120(4): 243-248. DOI: $10.1115 / 1.2829547$

43. Petetskii, V. N. 1995. Effect of the physical properties of slag on its formation when welding with a seamless flux-cored wire. Welding International 9(7): 573-575. DOI: 10.1080/ 09507119509548854

44. Suga, Y., and Hasui, A. 1986. On formation of porosity in underwater weld metal. IIW Doc. IX: 1388-1386. DOI: 10.2207/ qjjws1943.50.1225

45. Pope, A. M., Teixeira, J. C. G., Paes, M. T. P., dos Santos, V. R., Ros, D., and Domingues, J. R. 1997. Influence of water depth on microstructure and mechanical properties of wet welds. International Conference on Offshore Mechanics and Arctic Engineering 3: 13-19.

46. Sanchez-Osio, A., Liu, S., Ibarra, S., and Olson, D. L. 1993. Underwater wet welding electrodes. 12th International Conference on Offshore Mechanics and Arctic Engineering - Materials Engineering A: 119-128.

47. Sanchez-Osio, A., Liu, S., Ibarra, S., and Olson, D. L. 1994. Underwater wet welding consumables for offshore applications. IIW Doc. II: 1232-1294.

48. Santos, V. R., Monteiro, M. J., Rizzo, F. C., Bracarense, A. Q., Pessoa, E. C. P., Reppold, R., Domingues, J. R., and Vieira, L. A. 2010. Recent evaluation and development of electrodes for wet welding of structural ship steels. ASME $29^{\text {th }}$ International Conference on Ocean, Offshore and Arctic Engineering, Shanghai, China. DOI: 10.1115/OMAE2010-20808

49. Andrade, L. G. D., Silva, W. C. D., Ribeiro, L. F., Pessoa, E. C. P., Bracarense, A. Q., and Liu, S. 2010. The effect of base metal and core rod carbon content on underwater wet weld porosity. ASME $29^{\text {th }} I n-$ ternational Conference on Ocean, Offshore and Arctic Engineering, San Francisco, Calif. DOI: 10.1590/S0104-92242010000200010

50. Liu, S., and Rowe, M. D. 2002. Progress in underwater wet welding: The quintessential SMA consumables. Trends on Welding Research Conference, Pine Mountain, Ga., ASM International: 536-541

51. Trevisan, R. E., Schwemmer, D. D., and Olson, D. L. 1990. The fundamentals of weld metal pore formation. Materials Processing: Theory and Practices 8: 79-115. DOI: 10.1016/B978-0-444-874276.50009-5

52. Liu, S., and Pérez-Guerrero, F. 2004. Joint research program between MMS and Pemex/IMP underwater wet welding for offshore structures and pipelines in the Gulf of Mexico: Process maturation and technology transfer, phase I. Center for Welding, Joining and Coatings Research, Colorado School of Mines, Golden, Colo.

53. Liu, S., and Pérez-Guerrero, F. 2006. Joint research program between MNIS and Pemex/IMP underwater wet welding for offshore structures and pipelines in the Gulf of Mexico: Process maturation and technology transfer, phase II. Center for Welding, Joining and Coatings Research, Colorado School of Mines, Golden, Colo.

54. Silva, E. A., and Hazlett, T. H. 1971. Shielded metal arc welding underwater with iron-powdered electrodes. Welding Journal 50(6): 406-415.

55. Gooch, T. G. 1983. Properties of underwater welds. Part 1: Procedural trials. Metal Construction: 164-167.

56. Gooch, T. G. 1983. Properties of underwater welds. Part 2: Mechanical properties. Metal Construction: 206-216.

57. Liu, S., and Olson, D. L. 1996. The effect of altitude on welding. $4^{\text {th }}$ International Conference on Trends in Welding Research, Gatlinburg, Tenn., ASM: 347-352.

58. Chew, B. 1973. Prediction of weld metal hydrogen levels obtained under test conditions. Welding Journal 52(9): 386-s to 391-s.

59. Pessoa, E. C. P., Bracarense, A. Q., and Liu, S. 2008. Influência do teor de carbono do metal na variação de porosidade ao longo de soldas em soldagem subaquática molhada. IIW International Congress XXXIV, São Paulo. Consolda 1: 1-10.

60. Pessoa, E. C. P., Bracarense, A. Q., and Liu, S. 2008. Estudo do comportamento da porosidade ao longo de soldas subaquáticas molhadas multipasses. Metalurgia e Materiais 64: 150-152.

61. Bracarense, A. Q., Liu, S., Pessoa, E. C. P., and Pérez-Guerrero, F. 2004. Study of re-melt temper bead and polarity effects on porosity in under freshwater wet welds. $23^{\text {rd }}$ International Conference on Offshore Mechanics and Arctic Engineering - Material Symposium. ASME/OMAE, Vancouver, Canada: 20-24. DOI: 10.1115/ OMAE2004-51037

62. Pessoa, E. C. P., Bracarense, A. Q., Liu, S., and Pérez-Guerrero, F. 2005. Covered electrode temperature variation during wet welding and its influence on weld metal porosity. $23^{\text {rd }}$ International Offshore Mechanics and Arctic Engineering Conference - Material Symposium Advances in Structural and Pipeline steels. ASME/OMAE, Halkidiki, Greece: 13-16. DOI: 10.1115/OMAE2005-67411

63. Pessoa, E. C. P., Ribeiro, L. F., Silva, W. C. D., Bracarense, A. Q., dos Santos, V. R., Monteiro, M. J., and Andrade, L. G. D. 2010. Arc stability indexes evaluation on underwater wet welding. $29^{\text {th }} \mathrm{In}$ ternational Conference on Ocean, Offshore and Arctic Engineering, Shanghai, China, ASME: 195-201. DOI: 10.1115/OMAE2010-20876

64. Pessoa, E. C. P., Bracarense, A. Q., Pérez-Guerrero, F., and Liu, S. 2003. Study of porosity location in under fresh water wet welds. $22^{\text {nd }}$ International Offshore Mechanics and Arctic Engineering Conference - Material Symposium, ASME/OMAE, Cancún, Mexico: 185-191. DOI: 10.1115/OMAE2003-37291

65. Rodríguez-Sánchez, J. E., Rodríguez-Castellanos, A ., PérezGuerrero, F., Carbajal-Romero, M. F., and Liu, S. 2011. Offshore fatigue crack repair by grinding and wet welding. Fatigue \& Fracture of Engineering Materials \& Structures 34: 487-497. DOI: 10.1111/j. 1460-2695.2010.01541.x

EZEQUIEL CAIRES PEREIRA PESSOA (ezequielpessoa@letu. edu) is with LeTourneau University, Longview, Tex., and STEPHEN LIU (sliu@mines.edu) is with the Colorado School of Mines, Golden, Colo. 